\title{
Historical Trends of Polycyclic Aromatic Hydrocarbons (PAHs) in the Sediments of Toulon Bay (South of France)
}

\author{
Emmanuel Wafo ${ }^{1,}$, , Lydia Abou ${ }^{1}$, Alain Nicolay ${ }^{1}$, Pierre Boissery ${ }^{2}$, Cédric Garnier $^{3}$, \\ Henri Portugal ${ }^{1}$ \\ ${ }^{1}$ Chemistry Department Pharmaceutic, Analytical Chemistry Laboratory, Marseille, France \\ ${ }^{2}$ Agence Some Water, Marseille, France \\ ${ }^{3}$ Chemistry Department, Laboratory PROTEE, University of the South of Toulon, Toulon, France
}

\section{Email address:}

emmanuel.wafo@univ-amu.fr (E. Wafo), lydia.abou@univ-amu.fr (L. Abou), alain.nicolay@univ-amu.fr (A. Nicolay), henri.portugal@univ-amu.fr (H. Portugal), Pierre.boissery@eaurmc.fr (P. Boissery), c.garnier@univ-tln.fr (C. Garnier)

${ }^{*}$ Corresponding author

\section{To cite this article:}

Emmanuel Wafo, Lydia Abou, Alain Nicolay, Pierre Boissery, Cédric Garnier, Henri Portugal. Historical Trends of Polycyclic Aromatic Hydrocarbons (PAHs) in the Sediments of Toulon Bay (South of France). International Journal of Environmental Monitoring and Analysis. Vol. 5, No. 6, 2017, pp. 150-158. doi: 10.11648/j.ijema.20170506.11

Received: August 28, 2017; Accepted: September 8, 2017; Published: November 29, 2017

\begin{abstract}
The levels of 16 USEPA priority PAHs in surface sediments and four dated sediment cores from Toulon Bay were determined and characterized by strong implantation. The total PAH levels in the superficial sediments ranged from 0.30 to $34.11 \mathrm{mg} \cdot \mathrm{kg}^{-1}$ dry weight in the $0-5$ layer and from 0.34 to $54.68 \mathrm{mg} \cdot \mathrm{kg}^{-1}$ dry weight in the $5-10$ layer. The qualitative assessment of sediment samples revealed relatively high PAH levels compared with French reference values. The results indicated that the PAHs in Toulon Bay are of pyrolytic origin. Estimating the rate of sedimentation based on pronounced events, such as explosive growth in the use of petroleum products, major developments, and periods of conflict, can be used to follow the history of pollution based on its composition over a period of approximately 130 to 180 years, depending on the length of the cores.
\end{abstract}

Keywords: Toulon Bay, Sediment, PAHs, Pollution, Depth Profile

\section{Introduction}

For several decades, the continuous development of human activities has resulted in the discharge of massive amounts of waste into the environment. An important fraction of this pollution, which mainly results from rapid increases in urbanization and industrialization, is directly released into the atmosphere and soils. However surface waters receive large amounts of waste from industrial, agricultural and domestic sources in addition to runoff pollution from roads and construction sites. According to the USEPA's Toxic Release Inventory (TRI), more than 100,000 tons of industrial waste are discharged directly into rivers, lakes and coastal marine environments every year, and most of these effluents, particularly those produced by fossil fuel combustion or by the discharge of petroleum-related materials in the refining and chemical industries, are highly toxic [1]. These industrial wastes mainly include organic compounds, such as polycyclic aromatic hydrocarbons (PAHs), which adsorb to particles and reach the ground or surface water by deposition [2].

PAHs may be reintroduced into the water column via resuspension or trophic transfer and produce long-term adverse effects, such as reproductive abnormalities and cancers in mammalian species [3]. Our study focuses on evaluating the levels of PAH contamination in sediments of Toulon Bay, which is a semi-enclosed bay that is exposed to strong anthropic impacts and is where a large number of contaminants are dumped, leading to the progressive degradation of the environment. This degradation is exemplified by the nearly complete disappearance of Posidonia beds [4]. Within the time frame of this bay contract and based on prior diagnosis, the objectives of the preservation of the marine environment were set up, and 
actions to restore and valorize water quality were planned. To meet these requirements, the CARTOCHIM project for Toulon bay was initiated in 2008. Since the early 1990s, the PAH levels in surface sediments and cores from along most of the Mediterranean coast, including Toulon Bay and its surroundings, have been studied in our laboratory. Sediment can be considered as a record of geologic history that retains patterns from the past. Among the numerous principal components of organic pollution in the environment, special status is given to hydrocarbons from diverse origins (e.g., fossil fuel, biological, and pyrolytic origins) that are composed of only carbon and hydrogen. These compounds exhibit physical, chemical and toxicological properties that vary according to their molecular structures and are characterized as follows: low solubility; a very high partition coefficient that results in the adsorption and binding of the hydrocarbons to clay minerals and lipids, respectively; very high chemical stability, which explains their persistence in the environment; and clear carcinogenic or mutagenic activity for the heavier entities (4 to 6 aromatic rings).

The introduction of hydrocarbons to aqueous environments depends on how initial products are used, for example wood, carbon or petrochemicals undergo pyrolysis [5]. In all cases, one-time or regular accidental contributions (e.g., sludge from dredging, disposals) and inputs from effluents cannot be excluded. The dispersion of these pollutants in the coastal environment is highly dependent on the nature, inputs and characteristics of the material, including the adsorptive properties, mobilization and preferential movements of the material as a function of the tidal currents and bathymetry.

The aims of this study were to (a) describe the spatial and temporal distributions of PAHs collected in Toulon Bay, (b) estimate sediment toxicity with respect to reference values, and (c) identify events and estimate sedimentation rates based on pronounced events along the cores.

\section{Materials and Methods}

\subsection{Study Area and Sampling Sites}

Toulon Bay covers a large area (Figure 1) that extends to the open sea between Carqueiranne in the east and Cape Cepet in the west. Toulon Bay is surrounded by Mounts Caume, Coudon and Faron to the north, by the layered crystalline rock formations of Carqueiranne to the southeast, and by St. Mandrier in the west. Two natural bays are linked: a larger bay with an area of $31 \mathrm{~km}^{2}$ on the east side of Toulon Bay that has a semi-circular shape, opens to the Mediterranean and offers little shelter from easterly winds and a smaller bay on the west side of Toulon Bay that is protected by several promontories that provide shelter for harbors, docks and military, industrial, tourism and aquaculture activities. At the end of the 19th century, a pier was built between Mourillon and St. Mandrier $(1500 \mathrm{~m})$ to separate the two bays.

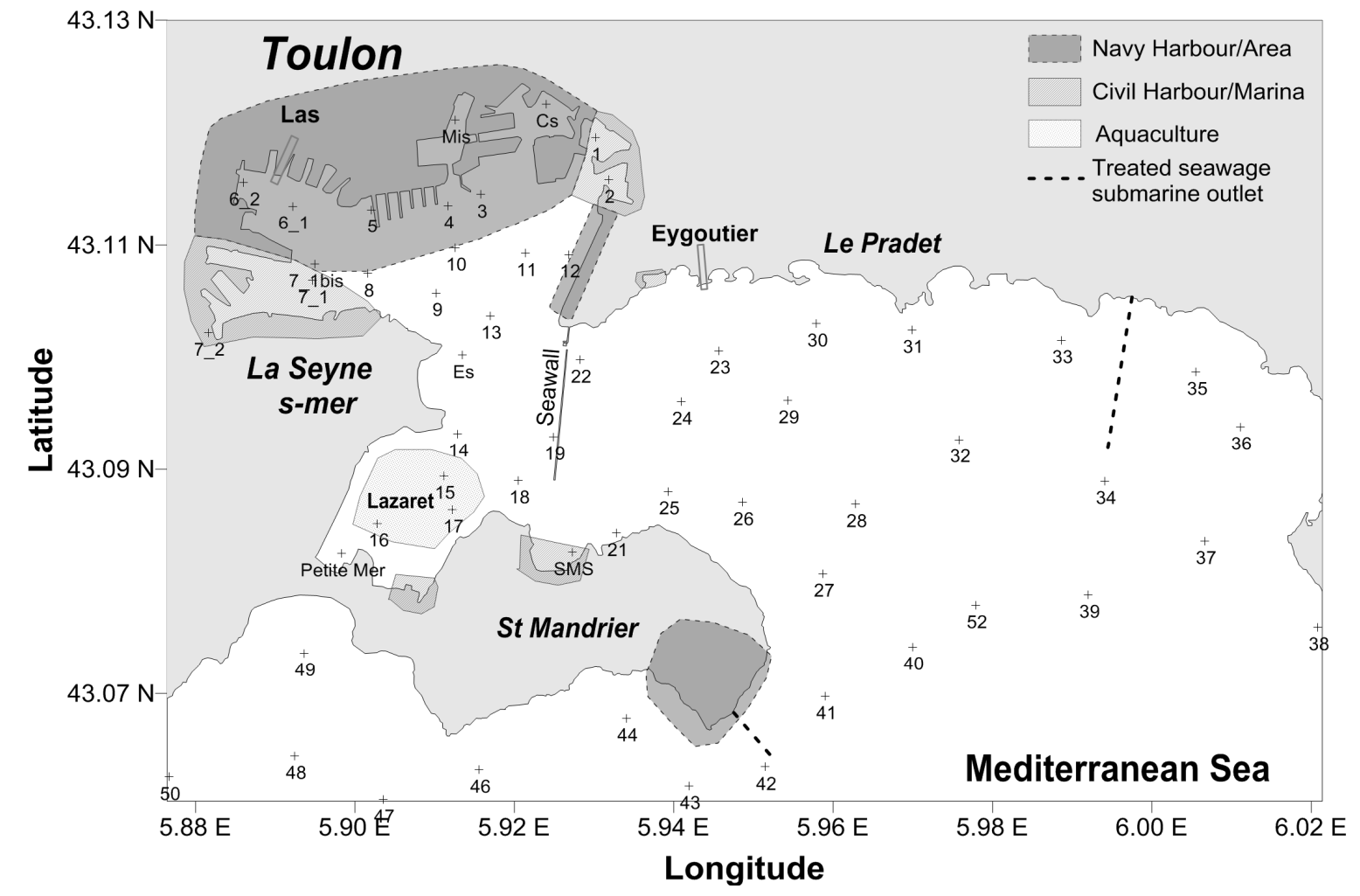

Figure 1. Map of the sampling sites in Toulon Bay.

Two rivers with relatively weak flow enter the Toulon Basin: the Eygoutier River $(12 \mathrm{~km})$ and the Las River $(8 \mathrm{~km})$.
These two rivers, which are subject to the Mediterranean tides, have always experienced severe and significant 
changes in water level. The Eygoutier River has been diverted to the larger eastern bay to reduce this problem. The depth profile of the water levels in Toulon Bay that resulted from storm events reveal two isobaths at depths of 50 and 60 $\mathrm{m}$ and $<2 \mathrm{~km}$ from the head of the canyon. These isobaths cut the continental slope to the south and along the axis of the bay.

The differences in the sea depth in the larger eastern bay and in the western bay were generally $<20 \mathrm{~m}$ and $>20 \mathrm{~m}$, respectively, and were accentuated by the construction of the pier. Sedimentation in the coastal zone was particularly enhanced in the harbors and coves (Bregaillon and Lazaret), with depths of $<10 \mathrm{~m}$. The communication channel between the bays decreased from $3 \mathrm{~km}$ to approximately $500 \mathrm{~m}$ due to the construction of the pier. A deeper channel was formed and is maintained artificially at a depth of $20 \mathrm{~m}$. This channel runs along the peninsular St. Mandrier and steeply slopes towards the center of the bay before joining the head of the canyon to the south. Because the expansion of Toulon Bay was closely associated with the expansion of the fleet and dockyards, military setbacks, including those of 1707, 1793 and 1942, resulted in major losses in ground installations, such as dockyards, harbors, forts, and munition and fuel suppliers. Major changes occurred after the Second World War. Although the naval strength remained after the Second World War, the shift to nuclear-powered aircraft carriers and submarines altered the impacts of the naval force on the environment. During the same years, commercial sea traffic significantly increased with the democratization of sailing for pleasure.

Additional changes have occurred as the metropolis of Toulon has grown to a population of nearly 600,000 . Toulon extends from Ollioules in the west to Pradet in the east and from La Seyne to St. Mandrier in the south. The conurbation of Toulon has grown rapidly, with large increases in industrial, commercial and tourism activities. The amounts of pollutants resulting from these activities have increased with runoff and outflow from impermeable surfaces.

\subsection{Sampling and Storage}

Different sampling campaigns were conducted in 2008 and 2009, with the help of the French Navy (boats, sediment corer, divers), to cover the whole Toulon's bay through surface sediment sampling at 54 stations using interface corer as described elsewhere [6]. We collected 'superficial sediment' samples by pushing $10-\mathrm{cm}$ long cylindrical tubes into the sediment at 39 points distributed across the basin of the bay. Each sample was subdivided into two parts, depths of $0-5$ and $5-10 \mathrm{~cm}$. Four cores representative of conditions at different sites in the bay over time (core 12 and 15 from the small bay and cores 23 and 52 from the larger bay) were collected to evaluate the changes in PAHs contamination with time. The cores were divided into $2-\mathrm{cm}$ slices under liquid nitrogen and stored at $-20^{\circ} \mathrm{C}$ before each subsample was analyzed from October 2010 to February 2011, as described above.

\subsection{Extraction Procedures for HPLC Determination of PAHs}

The PAHs extracted in this study included naphthalene (Nap), acenaphthene (Ace), acenaphthylene (Acy), fluorine (Fl), phenanthrene (Phe), anthracene (Ant), fluoranthene (Flu), pyrene (Pyr), benzo[a]anthracene (BaA), chrysene $(\mathrm{Chr})$, benzo[b]fluoranthene $(\mathrm{BbF})$, benzo[k]fluoranthene $(\mathrm{BkF})$, benzo[a]pyrene (BaP), dibenzo[a,h]anthracene (DBA), benzo[g,h,i]perylene (BgP), and indeno[1,2,3cd]pyrene (InP). These PAHs were extracted, purified and analyzed using a high-pressure liquid chromatography (HPLC) apparatus (Waters 2475 Alliance $^{\circledR}$, Milford, MA, USA) as described by [7].

\subsection{Quality Assurance Control}

The determination of recovery yields was performed by adding defined quantities of standard PAHs $(1 \mathrm{~mL}$ of $6.25 \mu \mathrm{g} / \mathrm{L})$ to $0.5 \mathrm{~g}$ of uncontaminated sediments. The spiked samples are purified in the same condition as unknown sediments and then analyzed by HPLC. For each compound the recovery is equal or superior to $85 \%$ and the mean recovery is around $90 \%$. The accuracy of the analytical results were checked by periodic analysis of standard reference material LGC6182- Sewage Sludge. Fourteen replicates of LGC6182 were first obtained on the same day to determine the average recovery and Standard deviation for each PAH compound. In the second time, in each serial of sample, the reference material is added at the end in order to check that the power of the ultrasonic bath doesn't diminish with the time. The results obtained from the reference materials were used to plot control charts and to determine if the data from each sample batch should be accepted or rejected. Rejected batches were reanalyzed. Before use, the glassware was cleaned using an appropriate detergent (TFD4 dec FT30), rinsed twice using tap water, and then dried at $100^{\circ} \mathrm{C}$ for at least 24 hours.

\section{Results and Discussion}

\subsection{Total PAHs and Fine Fraction $(F<63 \mu m)$}

The granulometry of the surface and cores sediments for this study were described and published in [8]. In the port areas, the total PAH levels range from 0.30 to $34.11 \mathrm{mg} \cdot \mathrm{kg}^{-1}$ (dry weight), with average concentrations of $10.91 \mathrm{mg} \cdot \mathrm{kg}^{-1}$, in the $0-5 \mathrm{~cm}$ layer and from 0.34 to $54.68 \mathrm{mg} \cdot \mathrm{kg}^{-1}$, with an average concentration of $11.45 \mathrm{mg} \cdot \mathrm{kg}^{-1}$, in the $5-10 \mathrm{~cm}$ layers. Generally, concentrations $<10 \mathrm{mg} \cdot \mathrm{kg}^{-1}$ are found around the large bay beyond Mourillon and the Carqueiranne Point. Concentrations $>10 \mathrm{mg} \cdot \mathrm{kg}^{-1}$ are localized to specific areas in the northern channel of the St. Mandrier peninsula, in the central portion of the bay beyond the head of the canyon (st. 52) to the mouth of the East Toulon outlet (st. 34); and south of the St. Mandrier peninsula after the Cap Cepet outlet (st. 42). The distribution maps (Figure 2A-B) reflect six concentration levels (1-5-10-20-50 and $>50 \mathrm{mg} \cdot \mathrm{kg}^{-}$ 
${ }^{1}$ ). Considering the affinity of organic pollutants for fine materials [2] and particularly clay-like materials, most of the PAHs analyzed are assumed to occur in the $<63 \mu \mathrm{m}$ fraction. The mobilization and transfer of PAHs are promoted by various mechanisms. Thus, the $<63 \mu \mathrm{m}$ fraction is more representative of the degree of sediment pollution, with the larger fraction essentially acting as a receptacle for this pollution. In the $0-5 \mathrm{~cm}$ and $5-10 \mathrm{~cm}$ layers, the PAH levels in the $<63 \mu \mathrm{m}$ fraction ranged from 0.50 to 67.78 and from 0.61 to $128.14 \mathrm{mg} \cdot \mathrm{kg}^{-1}$, respectively. The relative homogeneity of the granulometric composition of the $<63$ $\mu \mathrm{m}$ fraction had a smoothing effect on the values.

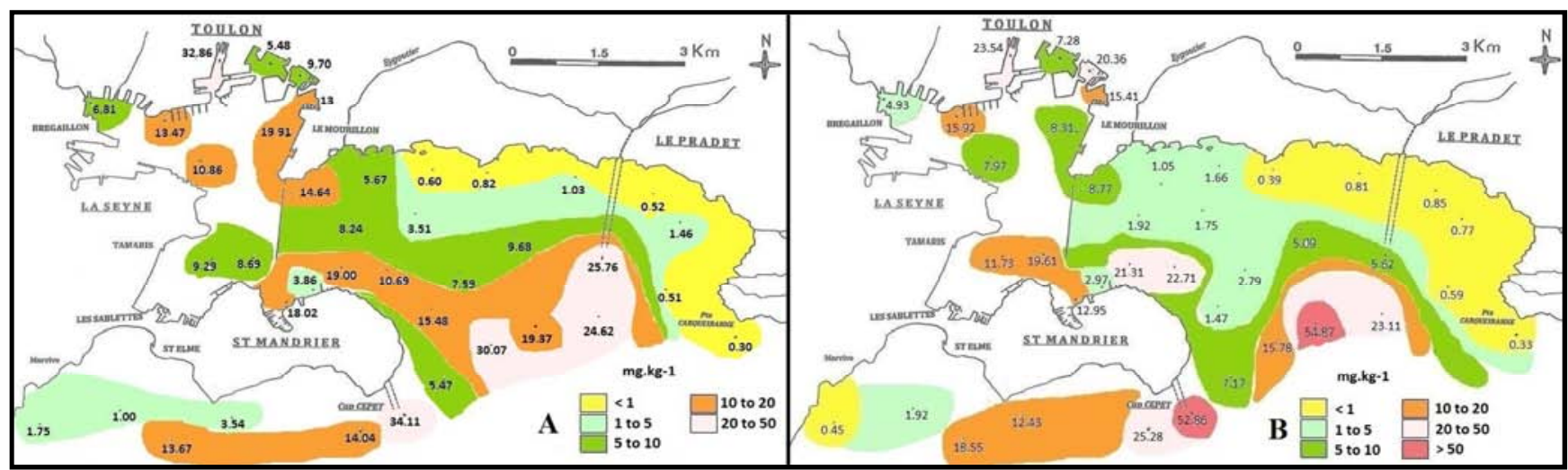

Figure 2. Spatial distribution of PAH concentrations throughout the bay.

Except for the port areas, where the range of values was high $\left(47\right.$ to $\left.6 \mathrm{mg} \cdot \mathrm{kg}^{-1}\right)$, the stations of the small bay exhibited more homogenous values (13 to $\left.18 \mathrm{mg} \cdot \mathrm{kg}^{-1}\right)$. The concentrations in the large bay varied within wide limits (17 to $\left.95 \mathrm{mg} \cdot \mathrm{kg}^{-1}\right)$, indicating particularly pronounced accumulation phenomena in the farthest part at the head of Toulon canyon.

\subsection{Principal Component Analysis (PCA) Representation for PAH Content and Grain Size of the 0-5 Cm Sample Sediment}

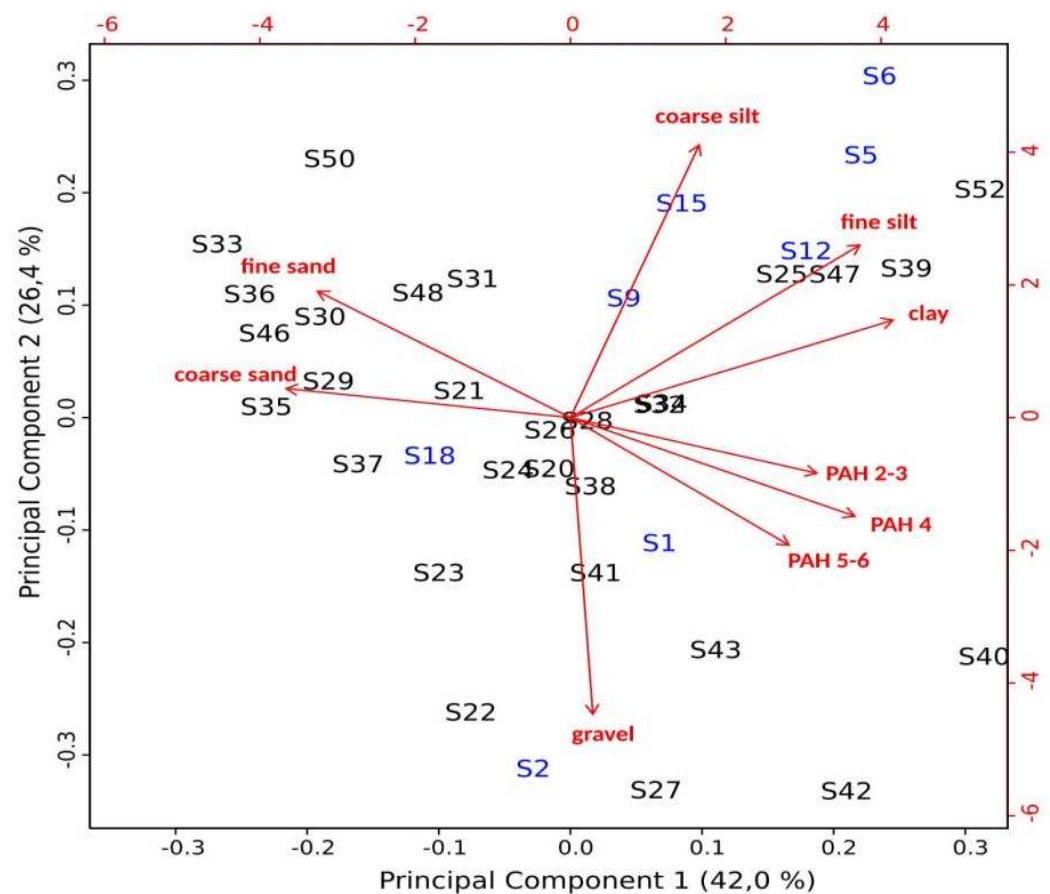

Figure 3. Principal component analysis representation for PAH contents and grain size of the 0-5 cm sampled sediments of the Toulon bay. The points located in the small bay are represented in blue and the points located in the large bay are represented in black color.

The substantial number of hydrocarbons and sampling stations prompted a search for simplification from a qualitative perspective. Principal component analysis (PCA) was carried out to check the similarity of samples based on their composition. The study is based on the PAH concentrations according the grain size values on all the studied stations. Two principal components were extracted, together explaining $68.4 \%$ of the total variance (PC1: $42 \%$; PC2: 26.4\%).

The Figure 3 shows that the samples formed globally three distinct groups. The first group unites the data points located in the left-hand side of the biplot stations $35,21,29,30,36$, $33,50,31,48,37,18$, which are characterised by high affinity on fine sand and coarse sand. The second group of 
stations are located at the right-hand upper side of the score plot, stations 9, 25, 47, 5-6, 39, 52, which are characterised by high affinity on fine silt and coarse silt. The last group of stations are located in the lower part of biplot, 22-23, 1-2, 27, 43, 41, 20-21, 38. This group, are characterised by high proportion of gravel, with the lower PAH concentrations. Finally, the PCA representation shows any real difference between the stations of the large bay compared to the samples from small bay. The concentrations of PAHs increase when the fraction of clay and fine silt increases, and on the contrary when the proportions in sands decrease. Normally, at a given sampling site, the fate of PAHs in shallow sediments depends on the transfer and sedimentation of particulate matter from a coastal site of origin to the site of accretion and on the stability of the conditions at the sampling site. According to the rings [2+3-, 4-, and 5+6rings], the graph shows that the PAHs varied all in the same thing, whatever the number of rings and in spite of the difference of chemical composition between the rings in the entire bay. The Toulon bay is heterogeneous and the PAHs composition most likely reflecting various local sources of PAHs contamination.

\subsection{Estimations of the Pollution Levels in the Bay Sediments}

The rules for dredging waste rely on reference data [9], and correspond to the concentration levels of pollutants that are likely present in sludge or silt in port areas. The PAHs used as references are: Flu, BbF, BkF, BaP, BgP, and InP. The mean values of these entities are expressed in $\mathrm{mg} \cdot \mathrm{kg}^{-1}$ of dry sediment and are categorized based on two threshold levels, $\mathrm{N} 1$ (1.5 mg. $\left.\mathrm{kg}^{-1}\right)$ and $\mathrm{N} 2$ (15 mg. $\left.\mathrm{kg}^{-1}\right)$, which correspond with marine and estuarine sediment dredging. Below the $\mathrm{N} 1$ level, the potential impact is considered neutral or negligible. Above the $\mathrm{N} 2$ level, the impact on the environment is demonstrated, and the dredged sediment is considered as hazardous waste that must be stored in an appropriate dump. The obtained results in our study, demonstrated that pollution covered nearly the entire bay (Figure 3 ).

To consider the current levels of PAHs from a global perspective, a comparison of concentrations in surface sediments from Toulon Bay and other locations around the world, is given in table 1 .

Table 1. Total world-wide concentrations of PAHs in surface sediment.

\begin{tabular}{|c|c|c|c|}
\hline Location & Total PAHs (ng.g $\left.{ }^{-1}\right)$ & Contamination level (a) & References \\
\hline Todos os Santos Bay, Brazil & $1,600-11,000$ & Very high & {$[10]$} \\
\hline Abu Qir Bay, Egypt & $242-3880$ & Moderate to high & {$[11]$} \\
\hline Dares Salaam, Tanzania & $77.9-24,600$ & Low to Very high & [12] \\
\hline North Adriatic Sea, Mediterranean Sea & $76,000-1520,000$ & Very high & {$[13]$} \\
\hline Bizerte lagoon, Tunisia & $50-20,000$ & Low to Very high & {$[14]$} \\
\hline The Persian Gulf, Bushehr, Iran & $41.7-227.5$ & Low to Moderate & {$[15]$} \\
\hline Aliaga Bay, Turkey & $70-20,940$ & Low to Very high & {$[16]$} \\
\hline Cyprus (Eastern Mediterranean) & $50-4752$ & Low to High & {$[18]$} \\
\hline Osaka Bay, Japan & $6.40-7765$ & Low to Very high & [19] \\
\hline Jinhae Bay, Korea & $12.4-2430,208$ & Low to Very high & {$[20]$} \\
\hline Bohai Bay, China & $6,300-535,000$ & Very high & [21] \\
\hline Gorgan Bay, Caspian Sea & $107.87-516.18$ & Moderate & {$[22]$} \\
\hline Gulf Fos area (Marseille) & $10,000-260,000$ & Very high & [23] \\
\hline Oludeniz Lagoon & $1390-1850$ & High & [24] \\
\hline Toulon Bay & $340-58,680$ & Moderate to Very high & This study \\
\hline
\end{tabular}

(a) Scale of the contamination level: low, 0-100; moderate, 100-1000; high, 1000-5000; very high, >5000 [25].

\subsection{Sediment Potential Human Toxicity and Biological Effects Based on PAHs}

The assessment of sediment toxicity in this study was performed based on the total concentration of potentially carcinogenic PAHs, $\Sigma$ CHAP: BaA, Chr, BbF, BkF, BaP, InP, DBA. The $\Sigma$ CHAP concentration varied from 76 to 13,831 $\mu \mathrm{g} / \mathrm{kg}$ d.wt, with a mean concentration of $3362 \mu \mathrm{g} / \mathrm{kg}$ d.wt. The potential toxicity of sediment was evaluated using the total toxic Benzo[a]pyrene equivalent $\left(\mathrm{TEQ}^{\mathrm{carc}}\right)[26]$. The $\left[\mathrm{TEQ}^{\text {carc }}\right]$ for all CHAP was calculated using the following relation: $\mathrm{TEQ}^{\text {carc }}=\Sigma \mathrm{i} \mathrm{C}_{\mathrm{i}} \mathrm{TEF}_{\mathrm{i}}{ }^{\text {carc }}$

Where $C_{i}$ is the carcinogenic PAHs concentration $\mu \mathrm{g} / \mathrm{kg}$ d.wt and $\mathrm{TEF}_{\mathrm{i}}{ }^{\text {carc }}$ toxic equivalency factors is the toxic factor of carcinogenic PAHs relative to Benzo[a]pyrene (BaP). Among all known potentially carcinogenic PAHs, BaPy is the only PAH for which toxicological data are sufficient for derivation of a carcinogenic potency factor [27]. According to US EPA [28], TEFs for BaA, Ch, BbF, BkF, BaP, InP, and DBA are $0.1,0.001,0.1,0.01,1,0.1$, and 1 respectively. In this study, the total $\mathrm{TEQ}^{\text {carc }}$ values of sediment samples varied from 46 (station 38) to 4456 (station 42) $\mu \mathrm{g}^{\mathrm{TEQ}} \mathrm{kg}^{-1}$ d.wt, with the mean value of $1341 \mu \mathrm{g}$ TEQ $\mathrm{kg}^{-1}$ d.wt. The higher total $\mathrm{TEQ}^{\text {carc }}$ values were found at stations 2, 5, 12, 22, 25, 27, 39, 40, 42, 43, Mis, SMS (varied from 2217 to 4456 $\mu \mathrm{g}$ TEQ $\mathrm{kg}^{-1}$ d.wt. Figure 4 shows the CHAPs and relative content of BaPeq dose in total TEQcarc. Among different CHAPs, contribution to the total TEQcarc decreased in the following order: $\mathrm{BaP} \quad(68.62 \pm 16.53 \%)>\mathrm{DBA}$ $(15.44 \pm 11.7 \%)>\operatorname{BaA}(9.11 \pm 8.93 \%)>\operatorname{InP}(3.51 \pm 3.35 \%)>$ $\operatorname{BbFl}(2.95 \pm 3.04 \%)>\operatorname{BkFl}(0.26 \pm 0.30 \%)>\mathrm{Ch}(0.11 \pm 0.10 \%)$. 


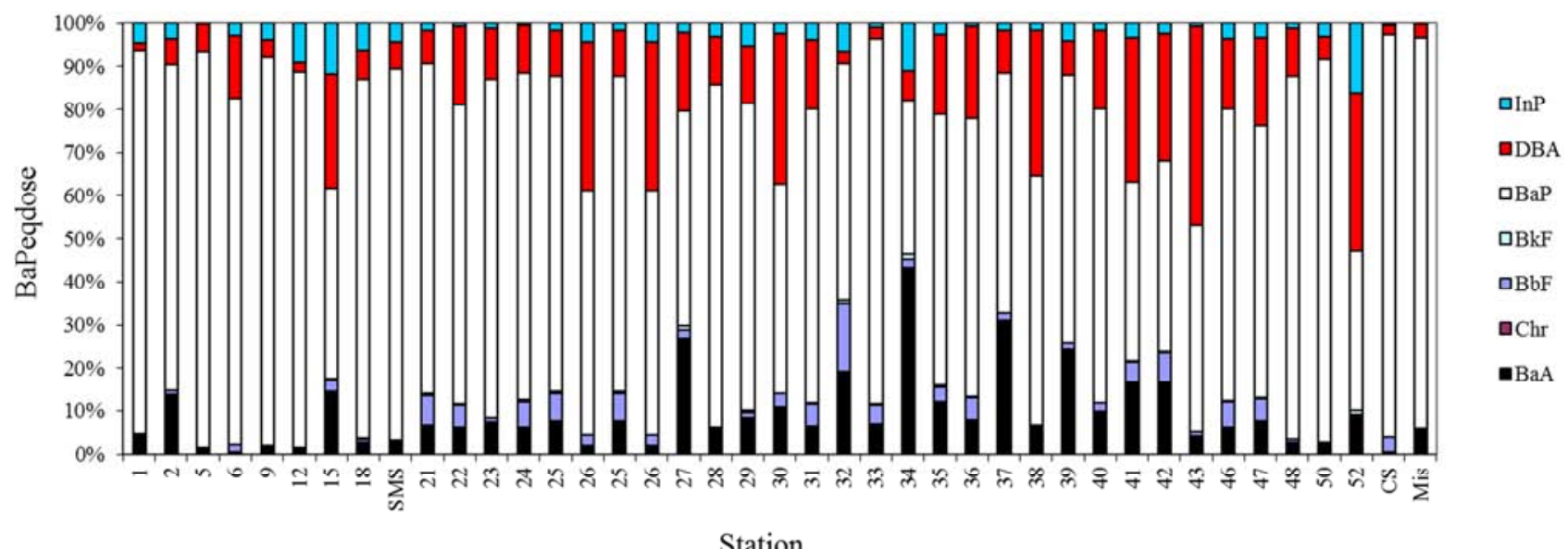

Figure 4. CHAPs and relative content of BaPeq dose in total TEQ $Q^{\text {carc }}$.

\subsection{Total PAH Concentrations in the Cores}

Comparison of the concentration profiles (Figure 5) in the different cores showing the following:

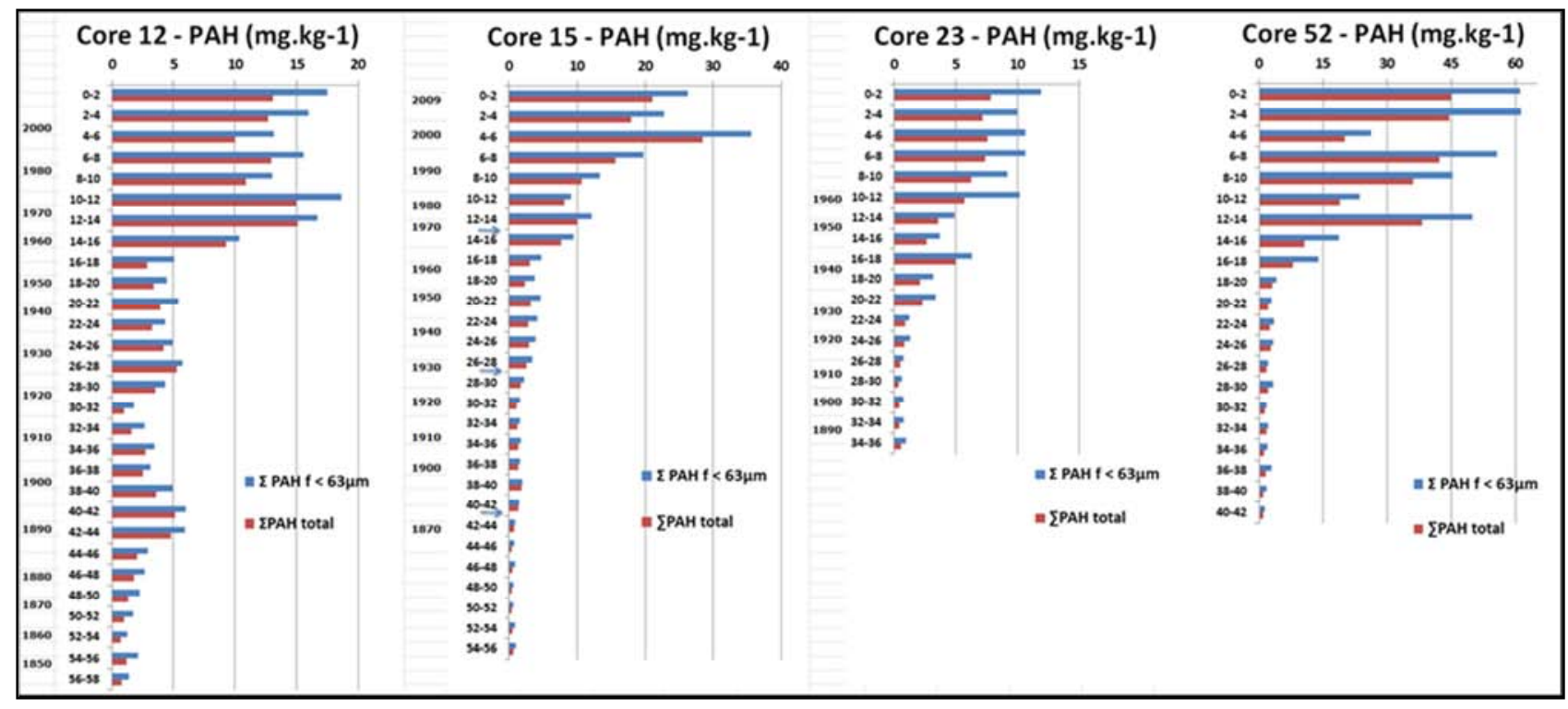

Figure 5. Depth profiles of PAH concentrations along the cores.

Two stations, 15 and particularly 52, exhibited very high PAH concentrations. At station 15, the evolution of the content was more regular and progressive from the bottom of the core to a depth of $28 \mathrm{~cm}$, with values not exceeding $2 \mathrm{mg} \cdot \mathrm{kg}^{-1}$. This increase is more pronounced between 28 and $10 \mathrm{~cm} \mathrm{(2} \mathrm{to} 10$ mg. $\left.\mathrm{kg}^{-1}\right)$. In more recent sediments, the concentrations of PAH reached values $>10 \mathrm{mg} \cdot \mathrm{kg}^{-1}$, with a maximum concentration of $35.6 \mathrm{mg} \cdot \mathrm{kg}^{-1}$ at a depth of $4-6 \mathrm{~cm}$. This value is essentially double the concentration for core number 12 .

As observed in the other cores, the sediment deposited at station 52 has massive variations in the input of PAHs, allowing a distinction to be made between an ancient period characterized by low concentrations (between 1 and 4 mg.kg${ }^{1}$ ) and a recent period for which the levels increase profoundly (from 10 to $60 \mathrm{mg} \cdot \mathrm{kg}^{-1}$ ). However, this core is different because the concentrations are 2 to 3 times higher than those in cores 12 and 15 , even though the latter are more substantial sources of pollution.

In core 12 , the evolution of concentrations occurs in three major and very different phases The first phase, between the bottom and $30-32 \mathrm{~cm}$, reaches a distinct and pronounced maximum at $44-40 \mathrm{~cm}$ in relation to an increase in the PAHs level in the fine fraction. The second phase is more irregular and is spread between 30 and $16 \mathrm{~cm}$, corresponding to an increase in the fine particle input. The third phase contrasts the previous phases and manifests itself as a massive increase from a depth of $14 \mathrm{~cm}$ and up, with a maximum value in the 10-12 $\mathrm{cm}$ layer. This period is accompanied by an increase in the fine fraction proportion from 70 to $87 \%$. Above depth, the levels fluctuate between 13 and $18 \mathrm{mg} \cdot \mathrm{kg}^{-1}$ in the fine fraction. Station 23 stands out because it exhibits concentrations that are distinctly lower than those found in the other cores. This 
station exhibits less contrast in the concentration increase. From 36 to $22 \mathrm{~cm}$, the PAH levels are constant and close to 1 mg. $\mathrm{kg}^{-1}$. Between 22 and $12 \mathrm{~cm}$, the progressive increase in the PAH levels is interrupted temporarily at $18-16 \mathrm{~cm}$, with a peak PAH level of $6 \mathrm{mg} \cdot \mathrm{kg}^{-1}$ associated with a brief increase in the PAH load in the $<63 \mu \mathrm{m}$ fraction. In the top $12 \mathrm{~cm}$, the concentration increases massively and becomes stabilize between 10 and $12 \mathrm{mg} \cdot \mathrm{kg}^{-1}$, with a ratio of nearly 2 between the fine fraction and the total sediment.

\subsection{Relative Distribution and Estimation of the Individual PAHs by Level}

The vertical distribution of PAH in the cores is presented in Figure 5. Previous studies on sedimentation [8] in Toulon bay estimate rates of $0.32 \mathrm{~cm}_{\text {year }}{ }^{-1}$ close to site 15 , while [6] found sedimentation rate of $0.27 \mathrm{~cm}_{\text {year }}{ }^{-1}$ with ${ }^{210} \mathrm{~Pb}$ activities for the same cores. Ours results provide a valuable basis for studying the chronology of sediment pollution in the smaller bay.

The compositions of the 4 cores are similar (Phe, Flu, Pyr being globally predominant), indicating homogeneous contamination and the same PAHs sources globally. From 58 to $52 \mathrm{~cm}$, core 12 exhibits a fairly homogenous composition in which no specific hydrocarbon moiety is particularly abundant. This section corresponds to the period from 1850 to 1860 , during which the bay was extensively exposed to the action of the sea. Between 52 and $30 \mathrm{~cm}$, which correspond to the period of $1860-1870$, the increase in total PAHs parallels that of Chrysene, which represents up to $50 \%$ of the PAHs. This period marks the beginning of the industrial era and the use of carbon as the main source for energy. The occurrence of these factors translates into an increase in the total level of hydrocarbons in the sediment, reaching a maximum toward the end of the $19^{\text {th }}$ century.

Between 30 and $16 \mathrm{~cm}, \mathrm{BaP}$, which was essentially absent in the lower levels, becomes dominant, with percentages of between 15 and $35 \%$. This period corresponds to the First World War. The decrease in BaP abundance corresponds with a decrease in the total PAH content and a return to a qualitative composition that is very close to that of the beginning of the preceding period (i.e., the $50-48 \mathrm{~cm}$ layer).

During the twenty years prior to the Second World War, the Mediterranean fleet contained 92 ships. Simultaneously, petroleum products, particularly fuel oil, took on a central role in energy production. Thus, the $\mathrm{PAH}$ pollution in the sediments reached a new peak in the $28-30 \mathrm{~cm}$ layer $(\approx 1920)$.

After 1942, the scuttling of the fleet, destruction of the arsenal and a large part of the town of Toulon, as well as the reconstruction that lasted until the end of the $1950 \mathrm{~s}$, was accompanied by a substantial stabilization of the PAHs composition in the sediments $(20$ to $16 \mathrm{~cm})$. The section from $14 \mathrm{~cm}$ up to $0 \mathrm{~cm}$ stands out for the nearly complete disappearance of low-molecular weight PAHs. This portion is representative of the full return of port activities, the development of the greater Toulon metropolitan area and the broad-based explosive growth of the consumption of petroleum products for domestic and industrial use during the 1960s.
Core 15 is marked by a predominance of InP, whose percentages were between 80 to $10 \%$ in three successive phases between 56 and $16 \mathrm{~cm}$. The period during which this component is dominant can be estimated as approximately 90 years (1870 to 1960). It is important to underscore this situation because it exemplifies the speed of the response of the environment to an event and the slowness of the "recovery" process that follows, unless a new event imposes its mark, as revealed in the upper part of the core where the level falls precipitously to $<8 \%$. Aside from InP, the variations of the observed proportions of other constituents are minor in amplitude. The quantitative and qualitative evolution of PAHs in this core reflects events that varied significantly and occurred successively in this area over the course of nearly two centuries.

The first event is the erection of the large pier in 1870 , which profoundly disturbed the nature of sedimentation inside the small bay. The second event occurred in 1960 after the Second World War, during a period of reconstruction of the civil and military ports. From 56 to $44 \mathrm{~cm}$, the sediments contain levels of fine materials from 62 to $75 \%$ and very low overall PAHs concentrations $\left(<1 \mathrm{mg} \cdot \mathrm{kg}^{-1}\right)$, which constitute a reference to the contribution of hydrocarbons that are essentially derived from pyrolysis (wood, carbon) in the sediments from Toulon bay before erection of the large pier in 1870 .

The following period (corresponding to 44 to $40 \mathrm{~cm}$ ) can be deemed as a phase where a return to equilibrium occurred following the disturbance associated with the erection of the large pier. Starting at a depth of 40-38 cm, the onset of the rapid regression of $\mathrm{InP}$ at this level is associated with the first increase in total PAHs (up to $2 \mathrm{mg} . \mathrm{kg}^{-1}$ ) and a decrease in the fine fractions. From $28 \mathrm{~cm}$ and up, a discrete decrease in the $<63 \mu \mathrm{m}$ fraction occurs up to $18-20 \mathrm{~cm}$ and a faster increase to a concentration of $4 \mathrm{mg} \cdot \mathrm{kg}^{-1}$ occurs at $20-22 \mathrm{~cm}$. This period, which we deem to be between 1890 and 1960, corresponds with an important phase in the Toulon history between the two World Wars (1914-18 and 1939-45) that saw the particularly pronounced expansion of the French fleet. The section above $16 \mathrm{~cm}$ corresponds approximately to 1960, with inputs to the $<63 \mu \mathrm{m}$ fractions. This change initially equates to PAHs values that increase from 10 to 35 mg. $\mathrm{kg}^{-1}$ in the $\mathrm{F}<63 \mu \mathrm{m}$ at $4-6 \mathrm{~cm}$ before decreasing to 26 mg. $\mathrm{kg}^{-1}$ at the surface. The predominance of 3- to 4-ring PAHs clearly indicates the impacts of the widespread use of petroleum products in a number of applications extending well beyond everyday port operations, even though 4-ring PAHs are also the main contributors to this predominance. With one exception, the relative composition of core 23 does not exhibit profound changes. The evolution of PAHs in this station reflects two eras, one in which small amounts of PAHs originate from the pyrolysis of traditional combustible materials (e.g., wood and carbon) and one that corresponds to the post-war period, which was marked by the use and general discharge of petroleum products aside from all maritime activity. The PAH profiles in this core indicate that the PAH composition is relatively constant from 36 to $18 \mathrm{~cm}$, 
with a predominance of molecules containing 2 to 4 rings. From 16-18 cm, the occurrence of an exceptional event at this level is evidenced by the massive contribution of 3 components (DBA, BaP and $\mathrm{Chr}$ ) that represent nearly $60 \%$ of the total PAHs. From $16 \mathrm{~cm}$ onward, the composition is characteristic of modern pollution, as observed in the other cores, with a preponderance of 3-4 rings.

Station 52 is unique to the collection of studied sites. Located on the seabed at a depth of $58 \mathrm{~m}$, station 52 is far from all direct sources of pollution. The formation of the deposits at station 52 arises mainly result from the transfer of particulate material through different routes (air, currents, dragging or sliding along the seabed). If transfer along the seabed plays a primary role in the formation of the deposit, it is facilitated by the very fine granulometry of the silt, for which the mean of the $2 \mu \mathrm{m}$ lower fraction is equal to $21.5 \%$. In common with the other cores, the sediments deposited at this station undergo massive variations in PAH inputs. This allows a distinction to be made between an ancient period characterized by low concentrations and a recent period during which the levels increase markedly.

The relative changes in the composition of the core from station 52 were similar to those observed for the core from station 15 , for which the most striking feature is the presence of a substantial and fluctuating proportion of InP from 17 to $40 \%$ between 42 and $18 \mathrm{~cm}$. These levels could correspond with phases of stagnation and the light replenishment of PAHs. Above this level, the percentage of this entity decreases to $8 \%$ and decreases toward the surface. Despite slight differences between the two series, the compositions suggest the same type of chemical pollution. However, the pollution was not necessarily accrued through the same sedimentary process.

Based on analogies with core 15 , the beginning of this deposition phase corresponds to the 1960 , which resulted in a sedimentation speed of $0.27 \mathrm{~cm}$ year ${ }^{-1}$. By adopting this estimation method, the $14-18 \mathrm{~cm}$ layers must represent the 1950-1960 timeframe, which was dominated by clearing for and then reconstructing the principal maritime and industrial installations of Toulon. These works likely resulted in the resuspension and release of materials that could reach station 15 by transferring through the trench that links the small bay with the head of Toulon canyon or by the settling of waste material from dredging the canyon head. The composition of this material is characterized by the prevailing presence of four PAHs (Ph, Ant, Flu, and Pyr) which account for $73 \%$ of the total PAHs. Further down in the core, diagnosis is harder to establish because a more limited PAH input is associated with frequent changes in the composition of the deposits for which the chronology is not clear. If one assumes the same sedimentation speed proposed for the upper part $(0.27$ $\mathrm{cm}$.year $\left.{ }^{-1}\right)$, the bottom of the core dates to the end of the $19^{\text {th }}$ century (approximately 1880).

\section{Overall Conclusions}

The concentration and sources of PAHs in surface sediments were studied, and a historical record was reconstructed based on dated sediment cores in the Toulon Bay. The total concentrations of the PAHs are responsible for a relatively extensive degree of pollution in the bay that can equal or exceed $10 \mathrm{mg} \cdot \mathrm{kg}^{-1}$ in some stations. The levels are reasonably consistent for comparing the levels found in others bays around the world. The estimation of the sedimentation rate based on pronounced events, such as an explosive growth in the use of petroleum products, major developments, and periods of conflict, provides an opportunity to follow the history of pollution based on its composition over a period of approximately 130 to 180 years, depending on the length of the cores. Overall, the cores provide evidence for a sharp contrast in concentrations that is indicative of the magnitude of current pollution loads. PAHs represent a permanent type of sediment contamination, but one that varies quantitatively and qualitatively over time. However, input during recent times (post 1950-60), due to the extensive use of petroleum products, is linked to massive variations in the concentrations and compositions of pollutants.

This work shows not only the substantial extent of this contamination in the total sediment but also the very high pollution potential in the $<63 \mu \mathrm{m}$ fraction, which increases markedly in cores 12, 15 and 52. This increase provides evidence for the process of accumulation for the most persistent hydrocarbons. Only the core at station 23 exhibits relatively low $\mathrm{PAH}$ levels, though still indicative of the impacts of the settling of run-off materials in the basin to the side of the Eygoutier River. In all cases, the predominance of Phe, Flu, Pyr, and Chr and the very weak contributions of lower molecular weight PAHs are indicative of the pyrolytic origin of the polluting petroleum product.

\section{Acknowledgements}

We would like to express our sincere gratitude to the French organization: Agence de l'Eau Rhône-Méditerranée et Corse for their financial support of this study.

\section{Disclosure Statement}

The authors declare that they have no competing interest.

\section{References}

[1] Watanabe, T., Ohe T., Hirayama, T. (2005) Occurrence and Origin of Mutagenicity in Soil and Water Environment. Environmental Science 12 (6): 325-346.

[2] Meador, J. P., Stein, J. E., Reichert, W. L., Varanasi, U. (1995) Bioaccumulation of Polycyclic Aromatic Hydrocarbons by Marine Organisms. Reviews of Environmental Contamination and Toxicology, 1143: 79-165.

[3] Dudgeon, D., Arthington, A. H., Gessner, M. O., Kawabata, Z., Knowler, D. J., Leveque, C., Naiman, R. J. (2006) Freshwater Biodiversity: Importance, Threats, Status and Conservation Challenges. Biological Reviews Camb Philosophical Society 81 (2): 163-182. 
[4] Bernard, G., Denis, J., Deneux, F., Belsher, T., Sauzade, D., Boudouresque, C. F., Charbonnel, E., Emery, E., Herve, G., Bonhomme, P. (2001) Etude et Cartographie des Biocénoses de la Rade de Toulon-Rapport de Synthèse Final. Contrat d'étude pour le SIAT, IFREMER et GIS Posidonie. IFREMER, 150p.

[5] Commendatore, M. G., Marina, L., Nievas, A., Amin, O. B., Esteves, J. L. (2012) Sources and Distribution of Aliphatic and Polyaromatic Hydrocarbons in Coastal Sediments from the Ushuaia Bay (Tierra del Fuego, Patagonia, Argentina). Marine Environmental Research 74: 20-31.

[6] Tessier, E., Garnier, C., Mullot, J. U., Lenoble, V., Arnaud, M., Raynaud, M., Mounier, S. (2011) Study of the Spatial and Historical Distribution of Sediment Inorganic Contamination in the Toulon Bay (France). Marine Pollution Bulletin 62 (10):2075-2086.

[7] Sarrazin, L., Diana, C., Wafo, E., Pichard-Lagadec, V., Schembri, T., Monod, J. L. (2006) Determination of Polycyclic Aromatic Hydrocarbons (PAHs) in Marine, Brackish, and River Sediments by HPLC, Following Ultrasonic Extraction. Journal of Liquid Chromatography and Related Technologies 29 (1): 69-85.

[8] Wafo, E., Abou, L., Nicolay, A., Boissery, P., Perez, T, Ngono Abondo, R, Garnier, C., Chacha, C., Portugal, H. (2016) A chronicle of the changes undergone by a maritime territory, the Bay of Toulon (Var Coast, France), and their consequences on PCB contamination. Springer Plus 5:1230.

[9] Alzieu, C. (2005) Evaluation des risques liés à l'immersion des boues de dragages des ports maritimes. In Programme national d'écotoxicologie: avancées récentes de la recherche. La documentation française 75-92.

[10] Celino, J. J., de Oliveira, O. M. C., Hadlich, G. M., Queiroz, A. F., Garcia, K. S. (2008). Assessment of Contamination by Trace Metals and Petroleum Hydrocarbons in Sediments from the Tropical Estuary of Todos os Santos Bay. Brazilian Journal Geology 38:753-760.

[11] Khairy, M. A., Kolb, M., Mostafa, A. R., El-Fiky, A., Bahadir, M. (2009) Risk Assessment of Polycyclic Aromatic Hydrocarbons in a Mediterranean Semi-Enclosed Basin Affected by Human Activities (Abu Qir Bay, Egypt). Journal of Hazardous Materials 170 (1):389-397.

[12] Gaspare, L., Machiwa, J. F., Mdachi, S. J. M., Streck, G., Brack, W. (2009) Polycyclic Aromatic Hydrocarbon (PAH) Contamination of Surface Sediments and Oysters from the Inter-Tidal Areas of Dar es Salaam, Tanzania. Environmental Pollution 157 (1):24-34.

[13] Dell'Anno, A., Beolchini, F., Gabellini, M., Rocchetti, L., Pusceddu, A., and Danovaro, R. (2009) Bioremediation of Petroleum Hydrocarbons in Anoxic Marine Sediments: Consequences on the Speciation of Heavy Metals. Marine Pollution Bulletin 58 (12):1808-1814.

[14] Garali, A. B., Ouakad, M., Gueddari, M. (2010) Contamination of Superficial Sediments by Heavy Metals and Iron in the Bizerte Lagoon, Northern Tunisia. Arabian Journal of Geosciences 3 (3):295-306.

[15] Mirza, R., Mohammadi, M., Sohrab, A. D., Safahieh, A., Savari, A., Hajeb, P. (2011) Polycyclic Aromatic Hydrocarbons in Seawater, Sediment, and Rock Oyster Saccostrea Cucullata from the Northern Part of the Persian Gulf (Bushehr Province). Water, Air, and Soil Pollution 223 (1):189-198.
[16] Neşer, G., Kontas, A., Ünsalan, D., Altay, O., Darılmaz, E., Uluturhan, E., Küçüksezgin, F., Tekoğul, N., Yercan, F. (2012) Polycyclic Aromatic and Aliphatic Hydrocarbons Pollution at the Coast of Aliağa (Turkey) Ship Recycling Zone. Marine Pollution Bulletin 64 (5):1055-1059.

[17] Bastami, K. D., Afkhami, M. Ehsanpour, M., Kazaali, A., Mohammadizadeh, M., Haghparast, S., Soltani, F., Zanjani, S. A., Ghorghani, N. F., Pourzare, R. (2013) Polycyclic Aromatic Hydrocarbons in the Coastal Water, Surface Sediment and Mullet Liza Klunzingeri from Northern Part of Hormuz Strait (Persian Gulf). Marine Pollution Bulletin 76 (1-2):411-416.

[18] Darılmaz, E., Kontaş, A., Uluturhan, E., Akçalı, İ., Altay, O. (2013) Spatial Variations in Polycyclic Aromatic Hydrocarbons Concentrations at Surface Sediments from the Cyprus (Eastern Mediterranean): Relation to Ecological Risk Assessment. Marine Pollution Bulletin 75 (1-2):174-181.

[19] Miki, S., Uno, S., Ito, K., Koyama, J., Tanaka, H. (2014) Distributions of Polycyclic Aromatic Hydrocarbons and Alkylated Polycyclic Aromatic Hydrocarbons in Osaka Bay, Japan. Marine Pollution Bulletin 85 (2):558-565.

[20] Yim, U. H., Hong, S. H., Ha, S. Y., Han, G. M., An, J. G., Kim, N. S., Lim, D., Choi, H. W., and Shim, W. J. (2014) Source- and Region-Specific Distribution of Polycyclic Aromatic Hydrocarbons in Sediments from Jinhae Bay, Korea. Science of The Total Environment 470-471:1485-1493.

[21] Zhou, R., Xuebo, Q., Shitao, P., Shihuai, D. (2014) Total Petroleum Hydrocarbons and Heavy Metals in the Surface Sediments of Bohai Bay, China: Long-term Variations in Pollution Status and Adverse Biological Risk. Marine Pollution Bulletin 83 (1): 290-297.

[22] Araghi, P. E., Bastami, K. D., Rahmanpoor, S. (2014) Distribution and Sources of Polycyclic Aromatic Hydrocarbons in the Surface Sediments of Gorgan Bay, Caspian Sea. Marine Pollution Bulletin 89 (1-2): 494-498.

[23] Mille, G., Asia, L., Guiliano, M., Malleret, L., Doumenq, P. (2007) Hydrocarbons in Coastal Sediments from the Mediterranean Sea (Gulf of Fos Area, France). Marine Pollution Bulletin 54 (5): 566-575.

[24] Tuncel, S. G., Topal, T. (2015) Polycyclic aromatic hydrocarbons (PAHs) in sea sediments of the Turkish Mediterranean coast, composition and sources. Environmental Science Pollution Research 22:4213-4221.

[25] Baumard, P., Budzinski, H., Michon, Q., Garrigues, P., Burgeot, T. and Bellocq, J. (1998) Origin and Bioavailability of PAHs in the Mediterranean Sea from Mussel and Sediment Records. Estuarine, Coastal and Shelf Science 47 (1):77-90.

[26] Qiao, M., Wang, C., Huang, S., Wang, D., Wang, Z. (2006) Composition, sources, and potential toxicological significance of PAHs in the surface sediments of the Meiliang Bay, Taihu Lake, China. Environmental International 32: 28-33.

[27] Peters, C. A., Knightes, C. D., Brown, D. G. (1999) Longterm composition dynanamics of PAH-containing NAPLs and implications for risk assessment. Environmental Science and Technology 33:4499-4507.

[28] Us EPA, (1993) Provisional Guidance for quantitative Risk Assessment of Polycyclic aromatic hydrocarbons EPA/600/R/089, Washington, DC: Office of Research and development, Us Environmental Protection Agency. 